\title{
Preimplantation genetic testing for inherited immunodeficiency
}

\begin{abstract}
Preimplantation genetic testing (PGT) has become a practical tool for at risk couples to avoid affected pregnancies and have a healthy progeny free from genetic and chromosomal disorders. PGT is also an option for stem cell transplantation treatment through combining PGT with preimplantation HLA typing for couples with children affected by congenital disorders, for whom no other alternative therapies are available, such as for congenital immunodeficiency. We present here our experience of 135 PGT cycles performed for 74 couples at risk for producing offspring with 18 different congenital immunodeficiencies, resulting in birth of 54 healthy children free from inherited immunodeficiency, which is one of the world's largest PGT series for immunodeficiency.
\end{abstract}

Keywords: preimplantation genetic testing, congenital immunodeficiency, HLA typing, $\mathrm{RhD}$ genotypes, CGD
Volume 6 Issue 6 - 2018

\author{
Svetlana Rechitsky, Tatiana Pakhalchuk, Maria \\ Prokhorovich, Geraldine San Ramos, Oleg \\ Verlinsky, Anver Kuliev \\ Reproductive Genetic Innovations, USA
}

Correspondence: Anver Kuliev, Reproductive Genetic Innovations, 2910 MacArthur Boulevard, Northbrook, IL 60062, USA, Email anverkuliav@hotmail.com

Received:September 13, 2018 | Published: November 06, 2018

\section{Introduction}

Preimplantation genetic testing (PGT) has become an established procedure not only for avoiding the birth of affected children with genetic and chromosomal disorders but, in contrast to prenatal diagnosis, also for having a healthy unaffected offspring. PGT has presently been performed for more than five hundred different conditions, resulting in birth of tens of thousands healthy children free of genetic disorders. ${ }^{1-3}$ It has been also applied for preimplantation HLA typing to obtain an HLA identical donor progeny and allow stem cell transplantation treatment for the affected siblings with genetic and acquired disorders, requiring HLA matched stem cell transplantation. $^{4-9}$

Hematological diseases are one of the largest groups of conditions for which PGT is being performed, including heamoglobinopathies (thalassemia and sickle cell disease), coagulopathies (hemophilia and aplastic anemias), and maternal fetal incompatibilities caused by the Kell (K1) and RhD genotypes. ${ }^{3}$

Severe congenital immunodeficiencies are an important group of conditions requiring PGT, to ensure the birth of unaffected children, who may also serve a potential stem cell donor progeny for the affected siblings. So PGT is frequently performed together with HLA typing, as HLA matched stem cell transplantation improves significantly the outcome of stem cell transplantation treatment, making PGT an obvious option for inherited forms of immunodeficiency. ${ }^{10,11}$

Feasibility of successful use of PGT for immunodeficiency has previously been reported for 36 patients, who produced healthy children free of immunodeficiency. ${ }^{11}$ So we present here our experience of 135 PGT cycles performed for 74 at risk patients resulting in birth of 54 unaffected children free of congenital immunodeficiency, which is one of the world's largest experiences.

\section{Material and methods}

A total of 135 PGT cycles were performed for 74 couples at risk for producing immunodeficiency progeny, including 26 for incontinentia pigmenti (IP), 24 for hyper-IgM type 1 immunodeficiency (HIGM1), 14 for chronic X-linked granulomatous disease (CGD),
10 for hypohidrotic ectodermal dysplasia with immune deficiency (HED-ID), 9 for Wiscott-Aldrich syndrome (WAS), 9 for ataxiatelangiectasia (AT), 7 for Type 1 X-linked agammaglobulinemia, 6 for Omenn syndrome (OMS), 5 for X-linked immunodysregulation, polyendocrinopathy and enteropathy (IPEX), 5 for autosomal recessive severe combined immunodeficiency, 5 for X-linked severe combined immunodeficiency (SCIDX1), 5 for chronic granulomatous disease, 5 for severe congenital neutropenia 1 (SCN1) and single cycle for each of the other five types of immunodeficiency listed in Table 1.

PGT cycles were performed using a standard IVF protocol coupled with micromanipulation procedures for the polar body, or embryo biopsy, described in detail elsewhere. ${ }^{12}$ The majority of cases were done by blastocyst biopsy, using laser assisted technology. To avoid misdiagnosis due to preferential amplification, multiplex nested PCR was performed, involving a simultaneous detection of the mutant genes together with up to three or more highly polymorphic markers, closely linked to the genes tested. With introduction of next generation sequencing (NGS) technology (Illumina, USA), whole genome amplification (WGA) was performed prior to genetic testing, allowing a simultaneous analysis of the chromosomal set of the embryo, which is becoming a routine additional procedure to improve the reproductive outcome of the PGT cycles. ${ }^{13}$ One or two immunodeficiency and aneuploidy free embryos, based on the information about the mutation testing, polymorphic markers and chromosomal analysis, were pre-selected for transfer back to patient, while other unaffected embryos were kept frozen for possible use by the patients. In those patients who have had a previous affected child with immunodeficiency, concomitant testing for HLA typing was performed as described elsewhere. ${ }^{12,13}$

\section{Results and discussion}

The results of PGT for immunodeficiency are presented in Table 1. A total of 171 unaffected were detected for transfer in $115(85.1 \%)$ of 135 PGT cycles performed for 74 couples carrying the above mentioned immunodeficiency mutations, resulting in 54 unaffected (47\% per embryo transfer) pregnancies, which yielded the birth of 54 healthy children free of immunodeficiency. The average number of embryos transferred in these cycles was 1.48 on the average. 
The data demonstrate the practical utility of PGT for avoiding the birth of children with congenital immunodeficiency, for which there is no effective treatment other than HLA matched stem cell transplantation. So PGT provides the couples at risk with the realistic option to avoid the affected pregnancy and have a offspring free of the disease.

As mentioned, if the couples have already had an affected child with immunodeficiency, PGT with HLA typing makes it also possible to have an access to the HLA identical stem cell transplantation through selection and transfer of those unaffected embryos which are also HLA match to the sibling. A complete cure was observed in our cases after stem cell transplantation in siblings, ${ }^{10,11}$ which is in agreement with the results of the other series. ${ }^{14,15}$
Although this is still a controversial issue, patients regard this option as the only opportunity to provide their affected children with HLA-matched bone marrow transplantation. The available experience demonstrates a highly successful stem cell transplantation treatment for siblings with such disorders, which may be recommended for a wider application to avoid the birth of affected children with immunodeficiency and for improving the access to HLA compatible stem cell transplantation. It may be expected that with introduction of a widespread preconception carrier screening programs couples at risk for producing offspring with congenital immunodeficiency could be identified prospectively, so to offer PGT to avoid the birth of affected children, while those with affected immunodeficiency children will benefit from PGT as a means for obtaining HLA matched donor progeny to achieve the effective stem cell transplantation treatment.

Table I Preimplantation Genetic Testing (PGT-M) for Congenital Immunodeficiency

\begin{tabular}{|c|c|c|c|c|c|c|c|c|c|}
\hline Disease & omim & Gene & \#Patient & \#Cycle & \#Transfers & $\begin{array}{l}\text { \#Embryo } \\
\text { transferred }\end{array}$ & Pregnancy & SAB & Birth \\
\hline Ataxia-Telangiectasia;AT & 607585 & ATM & 5 & 9 & 5 & 6 & 4 & 1 & 3 \\
\hline Agammaglobulinemia, X-Linked, Type I & 300755 & BTK & 4 & 7 & 7 & 13 & 3 & 0 & 4 \\
\hline $\begin{array}{l}\text { Immunodeficiency With Hyper-IGM, } \\
\text { Type I; HIGMI }\end{array}$ & 308230 & CD40LG & 12 & 24 & 18 & 26 & 8 & 1 & 7 \\
\hline $\begin{array}{l}\text { Granulomatous Disease, Chronic, } \\
\text { X-Linked; CGD }\end{array}$ & 306400 & CYBB & 10 & 14 & 13 & 19 & 6 & 1 & 5 \\
\hline $\begin{array}{l}\text { Immunodysregulation, } \\
\text { Polyendocrinopathy, And Enteropathy, } \\
\text { X-Linked; IPEX }\end{array}$ & 304790 & FOXP3 & 4 & 5 & 5 & 5 & 3 & 0 & 3 \\
\hline $\begin{array}{l}\text { Ectodermal Dysplasia, Hypohidrotic, } \\
\text { With Immune Deficiency }\end{array}$ & 300291 & IKBKG & 3 & 10 & 8 & 10 & 3 & I & 4 \\
\hline Incontinentia Pigmenti; IP & 308300 & IKBKG & 14 & 26 & 21 & 33 & 7 & 0 & 8 \\
\hline Omenn Syndrome (OMS) & 603554 & RAG I & 2 & 6 & 5 & 12 & I & 0 & 2 \\
\hline $\begin{array}{l}\text { Severe Combined Immunodeficiency, } \\
\text { Autosomal Recessive }\end{array}$ & 603554 & RAG2 & 2 & 5 & 4 & 7 & 2 & 0 & 2 \\
\hline Wiskott-Aldrich Syndrome;Was & 301000 & WAS & 5 & 9 & 10 & 17 & 6 & 0 & 6 \\
\hline $\begin{array}{l}\text { Lymphoproliferative Syndrome, } \\
\text { X-Linked, I; XLPI }\end{array}$ & 308240 & SH2DIA & 1 & I & 2 & 2 & I & 0 & I \\
\hline $\begin{array}{l}\text { Severe Combined Immunodeficiency, } \\
\text { X-Linked; SCIDXI }\end{array}$ & 300400 & IL2RG & 3 & 5 & 7 & 10 & 3 & 0 & 3 \\
\hline $\begin{array}{l}\text { Granulomatous Disease, Chronic, } \\
\text { Autosomal Recessive }\end{array}$ & $\begin{array}{l}233700 \\
233710\end{array}$ & $\begin{array}{l}\mathrm{NCFI} \\
\mathrm{NCF} 2\end{array}$ & 2 & 5 & 4 & 4 & I & 0 & 1 \\
\hline $\begin{array}{l}\text { Neutropenia, Severe Congenital, I, } \\
\text { Autosomal Dominant; SCNI (De } \\
\text { Novo) }\end{array}$ & 202700 & ELANE & 3 & 5 & 4 & 4 & 4 & 1 & 3 \\
\hline Immunodeficiency 2I; IMD2I & 614172 & GATA2 & 1 & I & 0 & 0 & 0 & 0 & 0 \\
\hline $\begin{array}{l}\text { Hyper-IgE Recurrent Infection } \\
\text { Syndrome,Autosomal Recessive }\end{array}$ & 611432 & DOCK8 & 1 & I & 0 & 0 & 0 & 0 & 0 \\
\hline $\begin{array}{l}\text { Hemophagocytic Lymphohistiocytosis, } \\
\text { Familial, 3; FHL3 }\end{array}$ & 608898 & UNCI3D & I & I & 1 & 2 & I & 0 & 1 \\
\hline $\begin{array}{l}\text { Platelet Disorder, Familial,With } \\
\text { Associated Myeloid Malignancy; } \\
\text { FPDMM }\end{array}$ & 601399 & RUNXI & 1 & I & 1 & 1 & I & 0 & I \\
\hline Total & & & 74 & 135 & 115 (85.1\%) & $|7|$ (I.48) & 54 (47\%) & 5 (9.2\%) & 54 \\
\hline
\end{tabular}




\section{Acknowledgements}

None.

\section{Conflict of interest}

Authors declare that there is no conflict of interest.

\section{References}

1. Preimplantation Genetic Diagnosis International Society (PGDIS). $16^{\text {th }}$ International Congress on Preimplantation Genetics. Reprod BioMed Online. 2018;36(Suppl 1):e1-e42.

2. Kuliev A, Rechitsky S. Current Challenges and Future Prospects. Expert Review in Molecular Diagnostics. 2017;17(12):1071-1088.

3. Kuliev A. Practical preimplantation genetic diagnosis. Second Edition. New York, London: Heidelberg, Springer; 2013.

4. Verlinsky Y, Rechitsky S, Schoolcraft W, et al. Preimplantation diagnosis for Fanconi anemia combined with HLA matching. JAMA. 2001;285(24):3130-3133.

5. Verlinsky Y, Rechitsky S, Sharapova T, et al. Preimplantation HLA testing. JAMA. 2004;291(17):2079-2085.

6. Rechitsky S, Kuliev A, Tur-Kaspa I, et al. Preimplantation HLA typing with preimplantation genetic diagnosis. Reproductive BioMedicine Online. 2004;6:488-493.
7. Kuliev A, Rechitsky S, Verlinsky O, et al. Preimplantation diagno sis and HLA typing for haemoglobin disorders. Reprod Biomed Online. 2005;11(3):362-370.

8. Rechitsky S, Kuliev A, Sharapova T, et al. Preimplantation HLA typing with aneuploidy testing. Reprod Biomed Online. 2006;12(1):89-100.

9. Verlinsky Y, Rechitsky S, Sharapova T, et al. Preimplantation Diagnosis for Immunodeficiencies. Reprod Biomed Online. 2007;14(2):214-223.

10. Kuliev A, Verlinsky Y. Preimplnatation HLA typing for stem cell transplantation treatment of genetic and acquired bone marrow failures. Reprod Biomed Online. 2004;9(2):205-209.

11. Anver Kuliev. Preimplantation genetic diagnosis for congenital immunodeficiencies. J Blood Disord Transfus. 2014;5(8):234.

12. Kuliev A, Rechitsky S, Verlinsky O. Atlas of Preimplantation Genetic Diagnosis. $3^{\text {rd }}$ ed. CRS Press, London: Taylor and Francis; 2014.

13. Rechitsky S, Pakhalchuk T, San Ramos G, et al. First systematic experience of combined PGD for single gene disorders and/or Preimplantation HLA typing with 24-chromosome aneuploidy testing. Fertil Steril. 2015;103(2):503-512.

14. Kahraman S, Beyazyurek C, Ekmekci CG, et al. Seven years experience of preimplantation HLA typing: a clinical experience of 327 cycles. Reprod Biomed Online. 2011;23(3):363-371.

15. Kahraman S. PGD for HLA: Clinical Outcomes of HLA compatible transplantation following PGD. Reprod Biomed Online. 2013;26(Suppl 1):S9-S10. 